\title{
A tessitura curricular e suas implicações no/do cotidiano de escolas de educação em tempo integral
}

\author{
Rafael Marques Gonçalves* \\ Graciele Fernandes Ferreira Mattos**
}

\section{Resumo}

No ano de 2006, iniciou-se o programa Escolas de Educação em Tempo Integral da rede municipal de ensino de Juiz de Fora. Concomitantemente ao programa, teve início o projeto de pesquisa e extensão "Tempos na escola", numa parceria firmada entre a Universidade Federal de Juiz de Fora(UFJF), a Secretaria de Educação da prefeitura de Juiz de Fora e as escolas de educação em tempo integral da rede municipal. No ano de 2010, as ações do grupo focalizaram a Avaliação do programa Escolas de Educação em Tempo Integral, cuja metodologia de pesquisa foi o trabalho com grupos focais constituídos pelos diversos segmentos integrantes da instituição escolar: alunos, professores, equipe administrativa (diretoras, vice-diretoras e coordenadoras pedagógicas), equipe de serviços gerais e mães de alunos. Neste texto, ${ }^{1}$ priorizaremos a discussão acerca da tessitura curricular e suas implicações no/do cotidiano das escolas de educação em tempo integral, discutidas e problematizadas pelos grupos focais. Para dar tom ao debate, vamos nos valer da discussão que embasa nossos modos de pensar/viver/sentir o mundo, perante o momento atual de crises e tensões paradigmáticas, que, de certa forma, vão influenciar as múltiplas maneiras com as quais criamos cotidianamente os conhecimentos e, com isso, tecemos os currículos em redes nos/dos/com os cotidianos.

Palavras-chave: Currículo, pesquisa no/do/com o cotidiano, educação em tempo integral.

\footnotetext{
* Mestrando em Educação pelo Programa de Pós-Graduação em Educação da Universidade Federal de Juiz de Fora(UFJF), Bolsista da Coordenação de Aperfeiçoamento de Pessoal de Nível Superior (CAPES), Professor da rede municipal de ensino de Juiz de Fora, Minas Gerais, Brasil.

** Doutoranda em Educação pelo Programa de Pós-Graduação em Educação da UFJF/MG, Bolsista da Fundação de Amparo à Pesquisa do Estado de Minas Gerais (FAPEMIG), Professora e Coordenadora da rede municipal de ensino de Juiz de Fora, Minas Gerais, Brasil.
} 


\title{
The tessitura curriculum and its implications for the daily life of schools in full time education
}

\begin{abstract}
In 2006, began the program Education Schools Fulltime municipal schools in Juiz de Fora. Concurrent with the Program began a project to research and extension "Times at school," a partnership between the Federal University of Juiz de Fora, Education Department and schools for full-time municipal network. In 2010, the group's actions focused on the Program Evaluation Schools Education Full-Time, whose research methodology was to work with focus groups composed by members of various segments of the school: students, teachers, administrative staff (principals, vice-directors and coordinators), general services staff and mothers of students. In this paper, we prioritize the discussion about the texture and its implications for curriculum/ daily-school full-time education, discussed and problematized by focus groups. To give tone to the debate, we have made use of the discussion that underlies our ways of thinking / living / experiencing the world, given the current moment of crisis andstress paradigm, which will go some way influence the multiple ways in which we create everyday knowledge and weave it into the curriculum networks in / for / withdaily.
\end{abstract}

Keywords: Curriculum, Search from the everyday, Education full time.

Desde o ano de 2006, acompanhamos na cidade de Juiz de Fora/MG a implantação e o desenvolvimento da ampliação do tempo diário de permanência dos alunos na escola, tendo como parâmetro a Lei de Diretrizes e Bases da Educação Nacional n. 9.394/96 que visa, proporcionar o pleno desenvolvimento de uma política educacional democrática e transformadora, na medida em que (re)pensa questões ligadas ao espaçotempo ${ }^{2}$ escolar e ao currículo no interior das instituições escolares.

Historicamente, a proposta de educação em tempo integral no cenário brasileiro está posta no movimento escolanovista das décadas de 1920 e 1930, como aponta Cavaliere (2002), caracterizando-se como uma ampliação das tarefas socioculturais presentes nas propostas políticas da época, um dos principais marcos históricos oriundos do Movimento Integralista, que nos anos 1930 defendia uma concepção de formação integral para um homem integral, aliada às doutrinas moralistas e de cunho religioso.

Num movimento contrário, surgiu, em meados do século XIX, uma proposta educacional socialista e utópica que viria a assumir a educação em tempo integral como bandeira política de ação libertadora e revolucionária. Uma proposta significativa foi quando Anísio Teixeira atuava como secretário de Educação do Estado da Bahia e inaugurou o Centro Educacional Carneiro Ribeiro (Escola Parque), que consistia em um complexo de quatro escolas e uma escola-parque, visando resgatar a qualidade do ensino. 
A tessitura curricular e suas implicações no/do cotidiano de escolas de educação em tempo integral

Na década de 1960, ocorreu a implantação de um projeto-piloto da educação para crianças da favela em cinco escolas da rede do antigo Estado da Guanabara (MAURíCIO, 2004), onde, além de frequentarem as aulas, as crianças tinham atendimento médico e psicológico. Duas décadas depois, a proposta de educação em tempo integral foi retomada com a construção dos Centros Integrados de Educação Pública - CIEPs no Estado do Rio de Janeiro.

Ainda nos anos 80, destacam-se também os Centros de Educação Integral (CEls) em Curitiba e as discussões acerca do desenvolvimento de dois programas na rede pública de educação no município e no Estado de São Paulo. Esboçando concepções administrativas e pedagógicas próprias, remetem em suas diretrizes à ideia de tempo integral em torno do objetivo de ampliar as oportunidades de aprendizagem por meio da diversificação das atividades e espaços escolares e não - escolares no contraturno, para além do tempo de permanência do aluno na escola.

Já na década de 90, as experiências de escolas de educação em tempo integral ficaram sob a responsabilidade do Governo federal. O projeto Minha Gente previa a implantação de 5.000 escolas de Ensino Fundamental em horário integral no país, denominadas Centro Integrado de Apoio à Criança (CIAC). Posteriormente, foi iniciado o Programa Nacional de Atenção Integral à Criança e ao Adolescente (Pronaica), cujos CIACs foram substituídos pelos Centros de Atenção Integral à Criança e ao Adolescente (CAIC).

Elementos comuns são possíveis de ser observados na concepção de educação em tempo integral nas propostas elencadas, como o trabalho voltado para o desenvolvimento do intelecto, do corpo, da saúde, da cultura e do trabalho, de forma a conceber o homem como um ser plural, que precisa ser trabalhado em suas diferentes potencialidades.

Entretanto, tais projetos político-educacionais caracterizam-se pelo descontinuísmo de suas propostas, revelando a fragilidade política e educacional quando se trata de atendimento à maioria da população.

Atualmente, se assiste à retomada das propostas de escola de tempo integral pelos governos estaduais e municipais como sendo a solução para o enfrentamento dos graves problemas educacionais, conforme preceituado em lei: "Progressivamente o ensino poderá ser ministrado em tempo integral, a critério dos sistemas de ensino" (BRASIL, 1996).

E foi justamente nesse contexto que, no ano de 2006, iniciou-se o programa Escolas de Educação em Tempo Integral da rede municipal de ensino de Juiz de Fora. Concomitantemente ao programa, teve início o projeto de pesquisa e extensão "Tempos na escola", numa parceria firmada entre a Universidade Federal de Juiz de Fora(UFJF), Secretaria Municipal de Educação e as escolas de educação em tempo integral da rede municipal. Durante os anos de 2006 
a 2010, profissionais das cinco escolas participantes do programa, técnicos da secretaria e pesquisadores da universidade refletiram sobre a implementação da educação em tempo integral no nosso município. Neste período, ocorreram reuniões semanais e encontros anuais para possibilitar a tessitura do conhecimento acerca deste modelo de educação.

Entendemos que, ao discutir a implantação deste programa, torna-se necessário entender que o conceito de escola de educação em tempo integral vai muito além de uma simples proposta de ampliação do tempo que os alunos permanecem nas escolas, pois pensar em educação em tempo integral significa repensar as propostas curriculares, repensar a formação de professores e mais uma série de compromissos em prol de uma educação disposta a romper com formas engessadas de se ver o mundo na modernidade, que se alicerça na tessitura do conhecimento-emancipação (SANTOS, 2006).

É pensando nisso que Gonçalves (2006, p. 8) ressalta que:

\begin{abstract}
Abordar a educação integral e o desenvolvimento de uma escola em tempo integral implica um compromisso com a educação pública que extrapole interesses políticos partidários imediatos; que se engaje politicamente numa perspectiva de desenvolvimento de uma escola pública que cumpra com sua função social, qual seja, a de socializar as novas gerações, permitindo-lhes o acesso aos conhecimentos historicamente acumulados, contextualizando-os e contribuindo na ampliação do capital simbólico existente, propiciando às crianças e jovens conhecer o mundo em que vivem e compreender as suas contradições, o que lhes possibilitará a sua apropriação e transformação.
\end{abstract}

No ano de 2010, as ações do grupo de pesquisa e extensão "Tempos na Escola" focalizaram a Avaliação do programa Escolas de Educação em Tempo Integral, cuja metodologia de pesquisa foi o trabalho com grupos focais constituídos pelos diversos segmentos integrantes da instituição escolar: alunos, professores, equipe administrativa (diretoras, vice-diretoras e coordenadoras pedagógicas), equipe de serviços gerais e mães de alunos. O foco de discussão dos grupos focais foi dar oportunidade aos diferentes sujeitos exporem e discutirem os desafios, avanços e perspectivas encontrados nos primeiros quatro anos de implantação da educação em tempo integral na rede municipal de ensino de Juiz de Fora.

Neste texto, priorizaremos a discussão acerca da tessitura curricular e suas implicações no/do cotidiano das escolas de educação em tempo integral, discutidas e problematizadas pelos grupos focais. Para dar tom ao debate, vamos nos valer da discussão que embasa nossos modos de pensar/viver/ sentir o mundo, perante o momento atual de crises e tensões paradigmáticas, 
A tessitura curricular e suas implicações no/do cotidiano de escolas de educação em tempo integral

que, de certa forma, vão influenciar as múltiplas maneiras com as quais criamos cotidianamente os conhecimentos e com isso tecemos os currículos em redes nos/dos/com os cotidianos.

A partir do trabalho de Santos (2007), buscamos trilhar caminhos em que são proclamados discursos de que vivemos em um momento de crise paradigmática entre a chamada modernidade e ao que se entende por pósmodernidade. ${ }^{3}$ Este autor fala em reconfiguração das concepções teóricas, políticas, sociais e econômicas, na medida em que buscamos reinventar as maneiras de ser, pensar, sentir e de fazer a sociedade, detida através das razões impostas pela modernidade. O caráter de crise paradigmática pauta-se no fato de que, para os problemas herdados da modernidade, não possuímos soluções modernas, alicerçando neste ponto o caráter de transição e reinvenção de novas bases epistemológicas.

Experimentamos um tempo confuso, de crise e de transição, sob a equação entre raízes, entendidas como o pensamento de tudo aquilo que é profundo, permanente, único e singular; e opções, quais sejam os pensamentos de tudo aquilo que é variável, efêmero e substituível. Para Santos (2008), a eficácia desta equação se assenta numa dupla astúcia e na necessidade de se reinventar o passado, viver o presente para assim vislumbrar um futuro.

Entendemos que com o passado - modernidade - aprendemos a dicotomizar homem e mundo, homens e homens, assim criando em nossas mentes a noção de individualidade. Entretanto, devido à constante crise e transição vivenciada pela atual pós-modernidade, tais dicotomias nos são (re)ensinadas e (re)criadas, configurando-se a importância da coletividade. Para tal, Santos (2006) define que, apesar de todo o perfil histórico de massacres epistêmicos culturais que carregamos, fomos e somos capazes de conceber a diversidade, a conflitualidade de ideias e opiniões como um tempo reflexo em que aguça à nossa cognição um ideal de solidariedade e de coletividade.

O que podemos apontar é que no projeto da modernidade predominou a lógica dicotomizadora da realidade, gerando uma separação entre objeto e sujeito, inserido neste contexto o coletivo como o que era social, muitas vezes usado por diferentes escolas de saberes como a designação de uma dada realidade oposta à dimensão do individual, o que nos leva a crer que o coletivo deveria passar a ser tratado como uma dinâmica de interações grupal.

A crise paradigmática repercute na crise da Educação, colocando inúmeros desafios no momento de se (re)pensar um projeto de recuperação e (re)qualificação da escola e da sociedade. O principal desafio, de acordo com Bonamino e Brandão (2002), é o de encaminhar uma proposta política de educação que diminua os problemas da escola e viabilize alternativas às questões postas pela complexidade desta. $E$ isso sem abandonar as exigências de uma educação comum para atender a uma população diversa. 


\section{Rafael Marques Gonçalves - Graciele Fernandes Ferreira Mattos}

Diante disso, a educação deve retomar seu compromisso de transformação social, sendo capaz de organizar uma sociedade em torno da solidariedade, igualdade e liberdade, conceitos e atitudes que durante toda a vivência humana foram compreendidos, mas que na prática, até então, nunca foram, de fato, garantidos e tidos como direitos de toda a humanidade.

Percebemos que a diferença no contexto do mundo pós-moderno ainda não é aceita, porque perturba, uma vez que possibilita que cada um se lembre de suas próprias limitações, de suas fragilidades, de suas incapacidades; por isso que a mulher perturba o homem, os alunos perturbam as professoras, os professores perturbam os pesquisadores.

E esta nossa incapacidade de lidar com a diversidade humana é construída e legitimada principalmente em nossa formação escolar e acadêmica. Nossa educação nos prepara para lidar com o que se encaixa em nosso padrão preestabelecido. Estudamos sobre o outro de acordo com as concepções e conhecimentos que temos desse outro, mas na realidade não o conhecemos, pois não o deixamos manifestar-se, emergir entre nós, ser conhecido, uma vez que estamos sobre a ilusão de igualdade que nos impede de conhecermos uns aos outros (SKLIAR, 2002).

A educação em geral, não somente a da universidade, separa os sujeitos em dois grupos: os outros, os diferentes, de quem a educação acredita possuir conhecimentos; e os mesmos, os capacitados, que definem a identidade daqueles, dos outros.

Nesse viés, a constituição da alteridade, segundo Guirado (1998), pressupõe o reconhecimento da diversidade, pois uma construtiva relação coletiva seria aquela que suporta a diferenciação. No grupo, cada um se constitui um a partir do outro, de suas relações e diferenças, e o outro se constitui outro a partir desta rede de subjetividades (SANTOS, 2006).

Contudo, possibilitar ao outro ser outro, diferente da mesmidade, causa dor, sofrimento por não aceitarmos os limites da diferença e da alteridade. Encontramo-nos numa estabilidade de convivência com os outros, vendo-os não como sujeitos, mas como desejamos enxergá-los; e, ao possibilitarmos uma mudança nessa relação que permita, de fato, o nascimento do outro, acabamos tendo que desconstruir tudo o que até então havíamos construído sobre ele e, pior, temos que nos reconstruir, pois agora não somos mais um em nós mesmos, mas nos tornamos dois, na conquista da alteridade.

Guirado (1998) afirma que todas as instituições sociais, inclusive a escola, são ocasiões para a reprodução da mesmidade e para a produção da diferença, uma vez que, diante de tantas certezas quanto à metodologia adequada, à boa relação entre professor e aluno, à melhor forma para a aprendizagem, a escola institui certos padrões de conduta, de pensamento e de discurso. 
A tessitura curricular e suas implicações no/do cotidiano de escolas de educação em tempo integral

A escola demarca nossos lugares e prevê nossos papéis. Mas, nas imperfeições, há espaçotempo para que ocorram descontinuidades, para que estranhamentos aconteçam na busca do reconhecimento da alteridade, mesmo que contra tudo e todos. Para tal, pensar a tessitura curricular e suas implicações no/do cotidiano das escolas de educação em tempo integral pressupõe levarmos em consideração o fato de que a estruturação dinâmica das atividades requer uma articulação entre as diferentes áreas de conhecimento, assim como um espaçotempo de diálogo constante entre os profissionais que atuam no cotidiano escolar de tempo ampliado, não na demarcação de fronteiras, e sim na superação que os limites modernos impõem.

Guará (2008) elucida que o conceito de educação integral como princípio organizador do currículo escolar pauta-se pela integração dos conhecimentos em abordagens interdisciplinares, transdisciplinares e transversais. $O$ que está em jogo, segundo o autor, é a necessidade de considerar a dinâmica da socialização e os processos educacionais ocorridos em diferentes espaçostempos e de modos variados, reconhecendo que não há um só modo de ensinar e muito menos um único processo de aprender, mas uma integralização de experiências e conhecimentos que podem se articular no processo educativo.

Tal afirmação demonstra complexidade, principalmente ao considerar a intensidade com que as experiências e vivências em tempo integral são tecidas, haja vista a significativa extensão de espaçostempos escolar. Trazendo à baila as discussões apontadas pelos participantes dos grupos focais, podemos delinear que a fragmentação da proposta curricular e do trabalho é interpretada como o principal desafio a ser superado.

A fragmentação das atividades pode ser percebida no discurso tanto de alunos quanto de professores:

\begin{abstract}
Moderadora: E à tarde o que vocês têm?
Orientação de estudo é: educação física, biblioteca, contação de história e artes; (grupo focal: aluna do primeiro segmento do Ensino Fundamental, maio de 2010).

Então de manhã nós temos as disciplinas normais do currículo básico funcionando e à tarde as oficinas. [...] Elas deveriam dar continuidade à proposta que você faz no turno da manhã. Isso às vezes não acontece. (grupo focal: professora do segundo segmento do Ensino Fundamental, maio de 2010)
\end{abstract}

No entanto, se refletirmos com base no discurso dos professores, podemos entender que os planejamentos de trabalho cotidiano esbarram na necessidade de um trabalho curricular que estabeleça interconexões tecidas cotidianamente pelos fios lançados por cada área, pressupondo um intenso e permanente diálogo entre as partes envolvidas, mas, como nos aponta Hora e 
Coelho (2004), "na grande maioria das vezes, a nossa preocupação é muito grande com o conteúdo da informação e nos esquecemos da forma como o comunicamos...". Em outras palavras, tendo em vista nossa formação científica moderna, sempre estamos inicialmente preocupados com a forma e/ou fôrma com que podemos nos valer para desempenhar nosso trabalho cotidiano e com isso refletir a estrutura curricular.

Compreendemos o cotidiano escolar, contrariamente ao pensado na modernidade, como um espaço de permanente negociação de sentidos, de criação e de (re)invenção permanente de saberesfazeres, valores e emoções; necessitando, de todos nós, sujeitos praticantes do ordinário (CERTEAU, 1994), frequente vigilância aos preconceitos e às buscas por práticas que se espera encontrar, em virtude do supostamente já sabido sobre a escola; numa tentativa de caminhar na contramão de um discurso hegemônico, que tudo define, classifica, nomeia, indo ao encontro de saberesfazeres contra-hegemônicos.

A negociação de sentidos e a invenção e (re)invenção permanente dos saberesfazeres referidos são possíveis em virtude dos "usos" que os sujeitos praticantes fazem dos produtos e das regras oferecidos para o seu consumo (CERTEAU, 1994). Portanto, a ampliação da compreensão sobre este dinamismo das realidades cotidianas exige estranhar o que parece familiar, consistindo em uma "virada" do olhar, conforme defende Certeau (2008).

Diante dessas discussões é que temos a convicção de que é preciso enfrentar a incapacidade de ver/ler/ouvir/sentir aprendida, que dá origem à cegueira epistemológica, buscando, por meio de trabalho sempre coletivo, superar as cegueiras desenvolvidas, incorporando aos possíveis modos de perceber 0 mundo convicções, saberesfazerese "sentires" diversos daqueles que formam, a cada momento, as redes de subjetividades que somos.

Valendo-nos de uma concepção de educação questionadora do paradigma da ciência moderna, que desagrega, fragmenta e formaliza os diversos campos do conhecimento humano em formas estanques e sem visão de totalidade, torna-se necessário propor uma estreita articulação curricular que procure contemplar o conhecimento de maneira mais abrangente, global e, portanto, integral.

A problemática anunciada em que as aulas de oficinas não dariam a devida continuidade ao trabalho desenvolvido no interior da sala de aula reflete $o$ risco que corremos ao entender que a tessitura curricular deva ser pautada apenas pelas disciplinas básicas, colocando estas como a principal detentora do conhecimento, desconsiderando que, quando articuladas de maneira interdisciplinar, as oficinas podem e devem também esperar que seu trabalho seja continuado pelas disciplinas básicas em constantes trocas. 
A tessitura curricular e suas implicações no/do cotidiano de escolas de educação em tempo integral

Oliveira (2007) considera necessário pensarmos o currículo de maneira contrária a uma simples lista de conteúdos e oficinas a serem trabalhados durante $o$ ano, criando cotidianamente naqueles que se prestam a fazer a escola, responsáveis pelo envolvimento dos saberes e processos interativos, a noção de que o currículo extrapola os seus muros e se encharca dos processos expressos nas nossas redes sociais.

Porque a gente acaba sendo engessado gente, não é pelo currículo não e não é pela cobrança de conteúdo não. É por nós não sabermos, eu acho que é o nosso desafio maior, é a gente conseguir a equipe saber, a equipe conhecer como trabalhar este currículo de uma forma transdisciplinar. A gente ainda não sabe. Nós não experienciamos isso. (grupo focal: equipe administrativa, maio de 2010)

Não nos ensinaram isto na formação, e fazer isso no dia a dia, o grupo tem que estar disposto. [...] Tem que envolver todo o grupo. (grupo focal: equipe administrativa, maio de 2010)

Os profissionais demonstram o desejo de, inicialmente, se atribuírem fôrmas, ou seja, maneiras de se fazer/pensar as práticas cotidianas, mas não podemos nos esquecer de que cotidianamente a repetição faz parte de nossas vidas, sendo isto fator primordial para deixarmos escapar aos nossos sentidos pequenos momentos oportunos para tecermos outros conhecimentos no coletivo escolar.

Podemos, então, apropriarmo-nos da forma como Certeau (2008) definiu a coletividade, como sendo "um lugar social que induz um comportamento prático mediante o qual todo usuário se ajusta ao processo geral do reconhecimento, concebendo uma parte de si mesmo à jurisdição do outro" (p. 47).

Daí porque temos, enquanto sujeitos praticantes do cotidiano, nos constituído enquanto comunidade investigativa que, para Wells apudPérez (2005), significa assumir um profundo sentimento de implicação e pertencimento a um coletivo. O processo educativo pensadopraticado como uma construção coletiva implica o questionamento permanente da organização das diferentes formas de poder e de se conhecer no/com o grupo. Nas palavras de Pérez (2005), viver a experiência da comunidade investigativa é tomar o cotidiano como objeto de reflexão, estranhá-lo, tendo como desafio permanente compreender o compreender do outro.

Nossa proposta reflexiva possui centralidade no discurso em prol da legitimação dos espaçostempos escolares, nos quais outros e tantos outros sujeitos se enveredam em usos, práticas, táticas e relações de trocas de saberesfazeres cada vez mais necessários. 


\section{Rafael Marques Gonçalves - Graciele Fernandes Ferreira Mattos}

Pensando que uma escola consolida-se enquanto tal a partir das estratégias e astúcias diferenciadas desenvolvidas por seus diferentes sujeitos em prol de um objetivo comum em se tratando de uma escola de educação em tempo integral, o desenvolvimento de uma educação emancipatória e crítica, tais estratégias e táticas, conhecimentos e necessidades são, quase sempre, negociados, ainda que alguns sujeitos não tenham certeza disso.

Alves e colaboradores (2004) apontam que "o movimento hoje necessário não é fazer uma proposta curricular em rede, mas sim fazer emergir as tantas redes trançadas cotidianamente nas nossas escolas e que na maioria das vezes ficam submersas" (p. 57). Nesse sentido, temos o discurso de que 0 que está proposto na teoria não estaria sendo realizado, mesmo quando estaríamos fazendo todo o trabalho de maneira submersa. Torna-se necessário fazermos emergir de nossos cotidianos aqueles saberesfazeres que, de acordo com as tessituras, são possíveis de ser tecidos, bastando estarmos de coração aberto para aproveitar cada momento de organização e diálogo possível, mesmo que de forma tímida.

[...] como trabalhamos em tempo integral, possuímos mais tempo para dialogar e discutir sobre os processos, há tempo para a troca de ideias, experiências dentro de cada disciplina. Quando marcamos de nos reunirmos à tarde, a professora da tarde vem pra podermos conversar. Isso ajuda muito. (grupo focal: professor do primeiro segmento do Ensino Fundamental, maio de 2010)

Como demonstrado no fragmento, é importante estarmos atentos ao fato de que cada escola de educação em tempo integral é única e, portanto, possui suas singularidades e diversidades, em um espaçotempo constituído por diferentes integralidades e multiplicidades epistemológicas que tornam possível a tessitura de tantas outras redes curriculares e de trabalho cotidiano.

No que se refere às escolas de educação em tempo integral, Moll (2009, p. 18) alerta para o fato de que "de nada adiantará esticar a corda do tempo: ela não redimensionará, obrigatoriamente, esse espaço", ou seja, se não tivermos a noção de que o contexto da educação integral acontece nos espaçostempos ampliados, e vice-versa, corremos o risco de nos prendermos apenas à noção do tempo, esquecendo-nos dos espaços que a corda do tempo esticada nos oferece.

...acho que cada dia é um dia de descoberta pra isso, acho que alguns relatos que nós tínhamos de escola de tempo integral não eram muito bem-sucedidos, né? Então eu acho que a gente já entrou um pouco com um certo pré-conceito com relação a isso, e lá na escola a gente teve até um desafio muito grande porque são três 
A tessitura curricular e suas implicações no/do cotidiano de escolas de educação em tempo integral

modalidades de ensino, educação infantil, fundamental I e fundamental II. (grupo focal: equipe administrativa, maio de 2010)

Podemos perceber nos trechos citados a importância de um trabalho conjunto e coletivo entre professores dos diversos segmentos de ensino e coordenadoras pedagógicas na tessitura curricular.

Eu fui fazendo isso com muita frequência. As professo-
ras de OE que é a nossa chamada Orientação de Estu-
dos, que é um projeto pra possibilitar a ampliação dos
momentos de leitura e de escrita, que nós criamos des-
de o ano passado na escola. Então, assim, eu sentava
com alguém pra planejar semanalmente, como que está
sua aula, o que a gente pode planejar. Então, isso me
deu, nesse ano, a possibilidade de saber como estava
cada turma, em que pé que estava. (grupo focal: equipe
administrativa, maio de 2010)

Essa negociação não é somente externa ao indivíduo, mas, sobretudo, interna, na medida em que nossas individualidades e coletividades nos constituem enquanto redes de subjetividades (SANTOS, 2006). Circulamos em muitos e variados espaçostempos, cada um destes fazem-nos exigências diferenciadas e, às vezes, antagônicas entre si. E nossas práticas escolares vão sendo tecidas nos contextos cotidianos, ampliando, aprofundando, redimensionando nossas redes de subjetividades.

A forma como vamos atuando com os profissionais da escola, com os alunos, com o conhecimento, produz constante movimento de ir-e-vir, que ora configura-se como saber e ora como ainda não saber, necessitando ser tecido outro saber, num ininterrupto movimento dialógico e dialético entre saber e ignorância (SANTOS, 2007).

Nos desdobramentos da prática pedagógica e de nossas ações na complexidade do cotidiano escolar, deparamo-nos com nossos saberes e nossas ignorâncias acerca dos processos de construção de uma educação em tempo integral que contemple e respeite a diversidade humana, compreendendo cada indivíduo em sua integralidade.

Alicerçados no sentimento de pertencimento a um grupo de pessoas que comungam de um mesmo ideal de educação, vislumbramos maiores possibilidades de luta por uma sociedade para todos com base em uma prática reflexiva coletiva que supere a abordagem individual e solitária. Contagiados pelo mesmo sentimento de pertença, mas não por pontos de vista, conhecimentos, práticasteoriaspráticas iguais, podemos, muitas vezes, ser tomados por formas múltiplas e/ou antagônicas de sabersentir. 
Entretanto, nessa incansável convivência coletiva, as partes se relacionam e constituem o todo, conforme um holograma, no qual a projeção das partes conservam suas próprias qualidades de relevo, de cor e de presença, devido ao fato de que cada parte inclui em cada um de seus pontos quase toda a informação do conjunto (MORIN, 1996).

\section{Referências}

ALVES, N., et al. Criar currículo no cotidiano. 2. ed. São Paulo: Cortez, 2004.

AZEVEDO, J. G. de. Fazer com paixão sem perder a razão: retalhos de uma experiência em escola pública de tempo integral. Rio de Janeiro: DP\&A, 2003.

BONAMINO, A. C. de; BRANDÃO, Z. Posfácio. In: BRANDÃO, Z. (Org.). A crise dos paradigmas e a educação. 8. ed. São Paulo: Cortez, 2002, p. 88102.

BRASIL. Lei n. 9.394, de 20 de dezembro de 1996. Estabelece as diretrizes e bases da educação nacional. Diário Oficial da União, Brasília, DF, 23 dez. 1996. Disponível em: <http://www.mj.gov.br/conade2.htm>. Acesso em: 03 jun. 2003.

CAVALIERE, A. M. V. Educação integral: uma nova identidade para a escola brasileira. Educação e Sociedade, v. 23, n. 81, p. 247-270, dez. 2002.

CERTEAU, M. de. A invenção do cotidiano. Artes de fazer. 1. ed. Petrópolis: Vozes, 1994. 2008.

A invenção do cotidiano. Morar, cozinhar. 2. ed. Petrópolis: Vozes,

COELHO, L. M. C. da C. Escola pública de horário integral: um tempo (fundamental) para o ensino fundamental, 2001. Disponível em: <http:// www.educacaoonline.pro.br/escola_publica.asp?f_id_artigo $=145>$. Acesso em: 08 mar. 2007.

FIGA, M. E. As outras crianças. In: LARROSA, J.; FERRÉ, N. P. de L. (Orgs.). Imagens do outro. Petrópolis: Vozes, 1998, p. 87-96.

GONÇALVES, A. S.; PETRIS, L. Escola de tempo integral - a construção de uma proposta. 2006. Disponível em: <http://www.nexusassessoria.com.br/ downloads/ETI_a_construcao_de_uma_proposta.pdf $>$. Acesso em: 13 ago. 2007

GUARÁ, I. M. F. R. Educação integral: articulação de projetos espaços de aprendizagens. Disponível em: <http://www.cenpec.org.br/modules/xt_conteudo/ index.php?id=46>. Acesso em: 08 jan. 2008. 
A tessitura curricular e suas implicações no/do cotidiano de escolas de educação em tempo integral

GUIRADO, M. Diferença e alteridade: dos equívocos inevitáveis. In: AQUINO, J. G. Diferenças e preconceito na escola: alternativas teóricas e práticas. São Paulo: Summus, 1998, p. 183-202.

HORA, D. M.; COELHO, L. M. C. da C. Diversificação curricular e educação integral. 2004. Disponível em: <http://www.unirio.br/cch/neephi/arquivos/ divercurriceducint.doc>. Acesso em: 20 dez. 2007.

LARROSA, J. O enigma da infância ou o que vai do impossível ao verdadeiro. In: LARROSA, J.; FERRÉ, N. P. de L. (Orgs). Imagens do outro. Petrópolis: Vozes, 1998, p. 67-86.

MAURÍCIO, L. V. Literatura e representações da escola pública de horário integral. Revista Brasileira de Educação, n. 27, p. 40-56, set./out./ nov./dez. 2004.

MOLL, J. (Org.). Educação integral: texto referência para o debate nacional. Brasilia: MEC/SECAD, 2009.

MORIN, E. Ciência com consciência. Rio de Janeiro: Bertrand Brasil, 1996.

OLIVEIRA, I. B. de. Aprendendo nos/dos/com os cotidianos a ver/ler/ouvir/sentir o mundo. Educação \& Sociedade, v. 98, n. 98, jan./abr. 2007.

PÉREZ, C. L. V. O Lugar da Memória e a Memória do Lugar na Formação de Professores: o cotidiano como espaço-tempo de reinvenção da escola, 2005. Disponível em: <www.anped.org.br/reunioes/26/trabalhos/ carmenluciavidalperez.rtf>. Acesso em: 20 dez. 2006.

SANTOS, B. de S. Pela mão de Alice: o social e o político na pós-modernidade. 11. ed. São Paulo: Cortez, 2006.

A crítica da razão indolente: contra o desperdício da experiência. 6. ed. São Paulo: Cortez, 2007.

. A queda do Angelus Novus: o fim da equação moderna entre raízes e opções. In: A gramática do Tempo: para uma nova cultura política. 2. ed. São Paulo: Cortez, 2008, p. 51-92.

SKLIAR, C. A educação que se pergunta pelos outros: e se o outro não estivesse aqui? In: LOPES, A. C.; MACEDO, E. (Orgs.). Currículos: debates contemporâneos. São Paulo: Cortez, 2002, p. 196-215. 


\section{Rafael Marques Gonçalves - Graciele Fernandes Ferreira Mattos}

\section{Notas}

1 Este artigo é fruto das discussões realizadas no projeto de pesquisa "Tempos na Escola" realizado entre 2006 e 2011, sob coordenação da Profa. Dra. Luciana Pacheco Marques e com financiamento do Conselho Nacional de Desenvolvimento Científico e Tecnológico (CNPq) e da Fundação de Amparo à Pesquisa do Estado de Minas Gerais (FAPEMIG).

2 Utilizaremos termos assim escritos por acreditar numa posição em que o modo dicotomizado de escrevê-los e entendê-los, calcado na modernidade, segue numa posição contrária ao modo como vem sendo necessário vê-los na pós-modernidade.

${ }^{3}$ O termo pós-modernidade será utilizado neste trabalho recuperando o alerta que Santos (2006) faz em que se vincula à impossibilidade momentânea de se cunhar uma expressão melhor.

\section{Correspondência}

Rafael Marques Gonçalves - Rua Santa Catarina, 160/429-H. Bairro São Bernardo, CEP: 36062-250, Juiz de Fora, Minas Gerais.

E-mail: rafamg@ig.com.br _ graciele_fernandes@yahoo.com.br

Recebido em 28 de março de 2011

Aprovado em 13 de novembro de 2011 